\title{
Changes of profession, employer and work tasks in later working life: an empirical overview of staying and leaving
}

\author{
Nina Garthe* (D) and Hans Martin Hasselhorn (D) \\ Department of Occupational Health Science, School of Mechanical Engineering and Safety Engineering, \\ University of Wuppertal, Wuppertal, Germany \\ ${ }^{*}$ Corresponding author. Email: garthe@uni-wuppertal.de
}

(Accepted 14 January 2021; first published online 8 March 2021)

\begin{abstract}
Occupational change encompasses change of profession, employer and work tasks. This study gives an overview on occupational change in later working life and provides empirical evidence on voluntary, involuntary and desired occupational changes in the older workforce in Germany. The analyses were based on longitudinal data from 2,835 participants of the German lidA Cohort Study, a representative study of employees born in 1959 or 1965. Multinomial logistic regression analyses were performed in order to characterise the change groups in their previous job situation. The findings indicate that occupational change among older workers is frequent. In four years, 13.4 per cent changed employer, 10.5 per cent profession and 45.1 per cent work tasks. In addition, the desire for change often remains unfulfilled: the share of older workers who wanted to but did not change was 17.6 per cent for profession, 13.2 per cent for employer and 8.9 per cent for work tasks. The change groups investigated differ in terms of their socio-demographic background, health and job factors such as seniority and leadership quality. In times of ageing populations, the potential of occupational change among older workers requires more consideration in society, policy and research. Special attention should also be paid to the group of workers who would have liked to change but feel that they cannot leave.
\end{abstract}

Keywords: employee turnover; career mobility; job lock; older workers

\section{Introduction}

In times of ageing workforces, strategies to extend the working life gain in importance. Currently, early exit routes from employment are reduced in many countries as a reaction to the demographic change. Moreover, older workers are encouraged to work longer (Conen et al., 2014). While today more employers are promoting sustainable employability (Pak et al., 2019), the responsibility for maintaining the employability still largely rests with the workers themselves. The rapid changes in

(C) The Author(s), 2021. Published by Cambridge University Press. This is an Open Access article, distributed under the terms of the Creative Commons Attribution licence (http://creativecommons.org/licenses/by/4.0/), which permits unrestricted re-use, distribution, and reproduction in any medium, provided the original work is properly cited. 
today's labour market and working life bring about new needs for adjustment among older workers, to guard against risks for an increasing person-job misfit and earlier exit from working life (Wong and Tetrick, 2017). Active strategies to maintain or promote person-job fit, health, work ability, motivation and-subsequentlyemployment participation of older workers may be occupational changes (Moen et al., 2016; Canivet et al., 2017).

Various disciplines, such as psychology, sociology, economics and occupational health, deal with occupational change - all from their own perspective. Therefore, reviewing occupational change literature offers different understandings and operationalisation of occupational changes (Bailey and Hansson, 1995; Liljegren and Ekberg, 2008; Nouri and Parker, 2013; Mantler et al., 2015; Canivet et al., 2017; Fernet et al., 2017; Hom et al., 2017; Rubenstein et al., 2018). Three forms of occupational change may be differentiated:

(1) A change of profession, meaning a change from one profession to another, which is often accompanied by retraining or further education and may end in a changed professional identity. An example is a change from salesperson to bus driver.

(2) A change of employer, meaning a change from one employer to another, typically while continuing to practise the same profession. Depending on the discipline, researchers use alternative terms such as turnover, transition, (external) job mobility or career change (Trevor, 2001; Morris, 2009; Hom et al., 2012; Alcover and Topa, 2018).

(3) A change of work tasks, meaning a change of work tasks within the workplace without changing profession or employer, e.g. by adding, omitting or modifying tasks.

The comparative investigation of these three forms of occupational change is rare. The only scientific publication differentiating between these forms known to the authors is provided by Feldman and $\mathrm{Ng}$ (2007), who review factors that enable or discourage employees to change profession, employer or jobs. With this broad conception of occupational change in mind, occupational changes may today be the rule rather than the exception among workers, not least in times of ageing work forces.

However, occupational changes pose a greater challenge for older workers than for younger workers. With increasing age, employees face age-related individual alterations in, for example, health, work ability or motivation, with work constituting one of the many underlying causes (Crawford et al., 2010; Kenny et al., 2016). Furthermore, there is a range of obstacles to occupational changes in later working life such as reduced envisaged pension entitlements, risk of wage loss, fear of insufficient qualifications, work identity, age stereotypes, being in a safe employment position or high security needs. Not least, the devaluation of experience, specific knowledge and skills acquired over years makes a change of profession or employer difficult (Bailey and Hansson, 1995). Even if wanted, many older workers may not initiate a change or retraining anymore, considering it to be 'too late'. They then tend to stay in the (potentially inappropriate) work situation or consider retiring earlier (Canivet et al., 2017). Thus, older workers may be reluctant to such changes, 
although research findings indicate that occupational change may sustain health and motivation (Canivet et al., 2017; Wong and Tetrick, 2017).

The three types of occupational change differ in their ways as to how they contribute to the sustainable employability of older workers. Changes of profession have the potential to leave professions with characteristic high mental or physical work demands, such as roofing, construction work or nursing, and workers may change to professions with a less-demanding work content (Aleksandrowicz et al., 2014). In contrast, job factors more related to work organisation, such as the quality of leadership and of social relations at work, are approved drivers for employer changes (De Raeve et al., 2008); this includes work-family incompatibilities (van Hooft et al., 2005). Here, a change of employer may bring along the improvement of such job factors without the need for a change of profession. While the first two forms of change require substantial efforts and individual risk taking, the third form, change of work tasks at the current workplace, may constitute low-risk - often stepwise and even reversible - solutions when the workers' resources and/or interests do not fit to the work demands. Such adaption of the work tasks on their own initiative may, for example, be part of a job crafting behaviour (Wong and Tetrick, 2017).

In the context of extending working lives, there is a need to understand better occupational changes of older workers. In today's research we find both - much scientific evidence on occupational change, but also evident research gaps. Most research and most theory is about changing employers. Here, cross-sectional studies are particularly common (Allen et al., 2014), the use of samples of specific occupational groups or employees of a particular organisation (Liljegren and Ekberg, 2008; Morris, 2009; Simon et al., 2010; Jahn and Ulbricht, 2011; Reineholm et al., 2012; Nouri and Parker, 2013; Mantler et al., 2015; Fernet et al., 2017), the investigation of determinants of employer changes (Rubenstein et al., 2018) and investigations focusing on younger employees (Nouri and Parker, 2013) or explicitly excluding older workers from the sample, because diverging causes and mechanisms are assumed (Adams, 2004). Voluntary employer changes were found to have the potential to improve adverse psycho-social working conditions as well as health and work ability for the workers (Liljegren and Ekberg, 2009; Garthe and Hasselhorn, 2020). Other researchers found a positive effect of voluntary employer changes on the workers' job satisfaction (Boswell et al., 2009; Chadi and Hetschko, 2014). For Germany, Grund (2009) confirmed that an employer change often resulted in a higher income level, more appropriate working hours, more job security, better possibilities for promotion, and a better match between person and work tasks. Significantly less research is found on changing the profession at higher working age; a focus lies on the nursing profession (Simon et al., 2010; Fernet et al., 2017), qualitative investigations (Jahn and Ulbricht, 2011) and only a few studies address older workers (e.g. Carless and Arnup, 2011). Australian researchers found that older workers and workers with a high tenure are less likely to change professions and that changes resulted in higher job satisfaction and reduced working hours (Carless and Arnup, 2011). Research from Germany showed that a change of profession resulted in a higher income level (Nisic and Trübswetter, 2012). Canivet et al. (2017) investigated another aspect of changes of profession. They confirmed that continued work in a non-desired profession has negative 
effects on mental health. Research on changes of work tasks usually takes place as part of research on job crafting (Tims et al., 2013; Wong and Tetrick, 2017). Job crafting encompasses changes of tasks as well as social and cognitive aspects of the job which are initiated by the employee in order to improve the personwork fit and work motivation (Wong and Tetrick, 2017). Studies on job crafting interventions found that job crafting even has the potential to increase the work engagement of older workers, especially among workers with a high workload (Kooij et al., 2020; Kuijpers et al., 2020).

Considering the risks and obstacles for change among older workers, two aspects may be particularly important to investigate: whether a change occurs voluntarily or involuntarily (Hom et al., 2017) and whether a change is desired or not (Huysse-Gaytandjieva et al., 2013). The voluntariness is considered in a few studies on employer changes only (Allen et al., 2014). Desired changes are studied by research on job lock or stuck at work (Stengård et al., 2016) and by using indicators such as willingness or intention to change and job search (Otto et al., 2009; Simon et al., 2010; Weng and McElroy, 2012; Nouri and Parker, 2013; Mantler et al., 2015; Alcover and Topa, 2018). Whether the gap between desired and actual change is especially prominent among older workers remains open and deserves increased scientific attention.

In summary, occupational change research usually uses small and selected, often cross-sectional samples and it is mostly focused on a specific concept of change. So far, a broad empirical overview and comparison of the three different forms of occupational change, their underlying causes, and the differentiation between merely desired and actual changes among older workers is lacking.

\section{Aim of the study}

Taking advantage of data from a large and representative cohort study of older workers, we want to contribute to a better understanding of occupational change among older workers in Germany by (a) depicting the frequencies of changes of profession, employer and work tasks among older workers considering possible overlaps of changes; (b) characterising change groups considering both sociodemographic, health and job factors, and also the degree of voluntariness/desire of the changes; (c) presenting self-reported main reasons for voluntary and desired occupational changes; and (d) discussing the obstacles and risks for change and the heterogeneity of the change groups among older workers. The conceptual basis of this paper is the theory on motivational states of staying and leaving by Hom et al. (2012).

\section{Theoretical background}

In their theory on motivational states of staying and leaving, Hom et al. (2012) define four employee groups, which in theory cover the complete range of actual and desired occupational changes. The authors combine the two dimensions (a) desired staying or leaving and (b) high or low perceived control of this preference. This results in four motivational states: enthusiastic leavers (EL), reluctant leavers 
(RL), enthusiastic stayers (ES) and reluctant stayers (RS), which are characterised by Hom et al. (2012) as follows:

(1) EL are characterised by having the desire and opportunity to change, leading to voluntary changing. Common reasons for the voluntary change are related to the job, such as adverse working conditions, conflicts with supervisors or colleagues, and outside job offers, as well as to the private life, such as relocating spouses or other family obligations. The typical EL is described as a low performer who often shows negative job attitudes resulting in a change of employer. Another type of EL is pulled away by attractive alternatives rather than pushed away from the previous job.

(2) RL have to leave against their will because they are forced to. They are also described as poor performers or having conflicts with supervisors while lacking job protections such as high tenure or contract obligations. Also, the combination of obsolete skills and high salaries are prominent among RL.

(3) ES are employees with high job satisfaction and commitment to their job, who neither want to change nor feel pushed to do so. ES remain with their employer as long as they can or until they retire, mostly because they are highly embedded in the job, for example, due to strong workplace links or sharing the employer's values and goals. However, some ES only stay because they are satisfied with their pay and job security or having a stress-free work situation.

(4) RS are those who stay because they feel they cannot leave although they would prefer to. They are characterised by the personal inability and/or the lack of alternatives to change although desired. Furthermore, some RS stay because otherwise they would face sacrifices such as giving up pension entitlements. Sometimes the desire to change does not even lead to an attempt to change. RS often have a person-job misfit as their skills do not match the job or the employer's values clash with their own. They do not just meet the minimum performance requirements; they also show work avoidance or counterproductive workplace behaviours.

Although the categorisation by Hom et al. (2012) is based on reviewing employee turnover, i.e. the change of employer, it may be expanded to all three forms of occupational change and provides a theory-based structure to our analyses.

\section{Method}

\section{Data and sample}

The analyses are based on data from the German lidA Cohort Study on Work, Age, Health and Work participation, a representative cohort study of socially insured older employees in Germany (www.lida-studie.de). The aim of lidA is to investigate work and employment in the ageing workforce. The study population consists of employees born in either 1959 or 1965 who were employed subject to social security contributions as of 31 December 2009. Thus, sworn civil servants (German: 
Beamte) and self-employed workers are not included. The social insured employees make up the largest part of the German labour force (about 86\%) (Hasselhorn, 2020). At 222 randomly chosen sample points across Germany, 26,697 randomly selected people were approached to participate in the study. In the first wave in 2011, 6,585 interviews were realised, resulting in a response rate of 27.3 per cent (Schröder et al., 2013; The American Association for Public Opinion Research, 2016), which is similar to that of other German surveys of comparable study design (e.g. Klaus et al., 2017). Participants are interviewed in their homes by computerassisted personal interviewing (CAPI). The data used in this article derive from the second wave in 2014 and the third wave in 2018 with 4,244 and 3,586 participants, respectively. A more detailed description of the lidA Cohort Study and its design has been given elsewhere (Hasselhorn et al., 2014). The lidA Study received ethical approval from the Ethics Commission of the University of Wuppertal dated from 5 December 2008 and 20 November 2017.

In order to focus on occupational changes between the two waves, study participants were excluded if they - in either wave - were not employed full time, part time or marginally, or if they were self-employed. The final sample consists of 2,835 participants aged 53 or 59 in 2018.

\section{Measures}

In the lidA Study (Wave 3,2018), questions to assess and examine the three different forms of changes (profession, employer, work tasks) were used in a specific succession (see Figure 1).

\section{Change}

To assess change of profession, participants were asked: 'In the last interview you said that your profession is [information from previous wave]. Is this still the case? (yes/no)'. Change of employer was assessed by the question: 'Have you changed your employer since the last interview? (yes/no)'. Change of work tasks was assessed by: 'Have your work tasks changed significantly in the last three years? (yes/no)'.

\section{Voluntariness of change (EL and RL)}

For change of employer and work tasks, the participants were asked whether they changed on their own initiative, on the initiative of the employer or under other circumstances. This question allows distinguishing between EL and RL. The question was not asked in the case of change of profession.

\section{Desired change (ES and RS)}

Where there was no change, the participants were asked whether they would have liked to have changed since the last study interview. The responses enable us to identify ES and RS.

\section{Attempt to change}

Finally, if participants would have liked to have changed, they were asked if they had attempted to change. This gives further insight to the group of RS. 


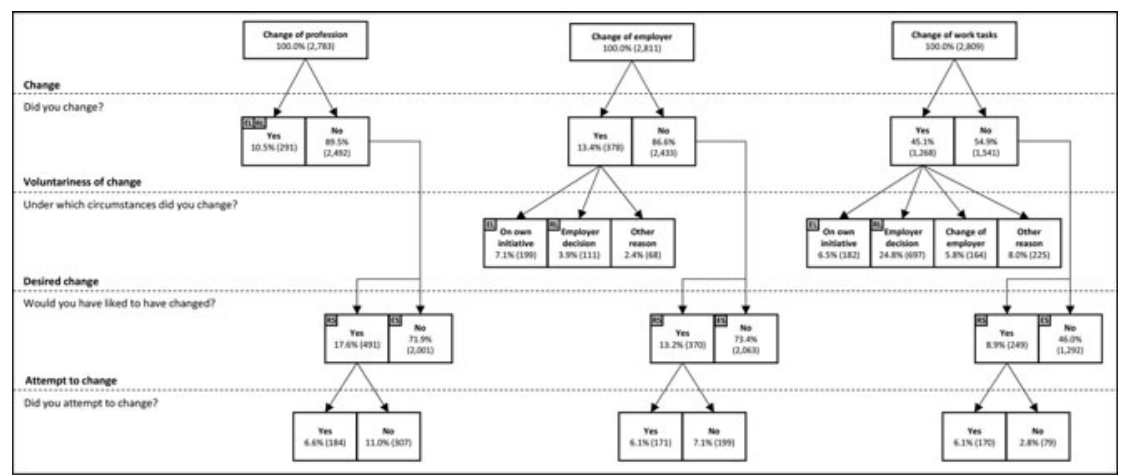

Figure 1. Empirical overview of occupational changes in later working life.

Notes: EL: enthusiastic leavers. RL: reluctant leavers. ES: enthusiastic stayers. RS:reluctant stayers.

\section{Main reason for change or desired change}

If the participants had changed on their own initiative (EL) or if participants had not changed, but would have liked to have changed (RS), they were asked to select a main reason for the change, or for the desire to change, from a list. The lists of potential main reasons differed slightly between the three forms of change, but were identical for actual and desired changes. Response options were: better working conditions, better salary, better working hours, occupational career, accident at work, health reasons, work-family conflict, avoiding unemployment (not for change of work tasks), another profession after retirement (only for change of profession), want to do something new (only for change of work tasks), other reason.

\section{Socio-demographic factors, health and job factors}

Socio-demographic background information, health measures and job factors assessed in Wave 2 (2014) were used to characterise the change groups in their previous job situation. The socio-demographic factors include gender (male, female), year of birth $(1959,1965)$, partner status (yes, no) and the job task requirement level of task complexity and occupational area (un-/semi-skilled task, skilled task, complex task, highly complex task).

Mental and physical health was assessed with the established Short Form Health Survey, SF-12 (Ware et al., 1995, 1996; Nübling et al., 2006). Component scores ranging from 0 to 100 were calculated for each health indicator; high values indicate better health.

The job factors include weekly working time (full time, part time, marginal employment), seniority (length of affiliation to the employer in years), individual income level (up to $€ 450, € 450-1,499, € 1,500-2,999$, $€ 3,000$ and more), and physical workload which includes three factors: (a) crouching, kneeling, lying or working overhead, (b) lifting or carrying heavy loads and (c) one-sided physical activity (never, up to one-quarter of the time, more than one-quarter of the time). Furthermore, four psycho-social work factors were assessed with scales from the Copenhagen Psychosocial Questionnaire (COPSOQ-II, middle version; Pejtersen et al., 2010): leadership quality, influence at work, possibilities for development 
and work-family conflict. Scores range from 0 to 100 with high scores indicating a high expression of the concept. Distributions and means of socio-demographic factors, health measures and job factors for the full sample are shown in Table 1.

\section{Analysis}

In line with our research aims, we provide descriptive information on the prevalence of the three forms of occupational change, the overlap of changes, their voluntariness, desired changes, possible attempts and the most frequent main reasons (for actual changes on own initiative (EL) and desired changes (RS)). Multinomial logistic regression analyses were performed for each of the three forms of occupational change in order to characterise the change groups in their previous job situation, considering socio-demographic background information, health measures and job factors assessed in Wave 2 (2014). The highest significant correlations between the independent variables were found for weekly working time and individual income level $(r=0.615)$, weekly working time and gender $(r=0.540)$, and gender and individual income level $(r=0.394)$. In each of the three models, the group of ES served as the reference group. All statistical analyses were performed using SPSS version 26.0.

\section{Results}

Figure 1 gives an overview of the proportions of EL, RL, ES and RS among older workers, aged 53 or 59 in 2018, for the three forms of occupational change: change of profession, employer and work tasks. The most common changes are changes of work tasks (45.1\%), 13.4 per cent reported a change of employer and 10.5 per cent a change of profession. There were more EL (7.1\%) than RL (3.9\%) among employer changers, but considerably more RL (24.8\%) than EL (6.5\%) among work task changers. However, for all forms of occupational change the majority of older workers were stayers. Yet, within this group, considerable numbers of RS were found. With regard to changes of profession, employer and work tasks, the proportions of RS (17.6, 13.2 and 8.9\%, respectively) were higher than the respective proportions for EL. About every third RS (unsuccessfully) attempted to change profession, about every second RS attempted to change employer and two out of three RS attempted to change work tasks.

Figure 2 depicts the overlap of occupational changes. Here, only participants with valid responses to all change questions could be included. Most of the changes of profession went along with changes of employer or work tasks. Only a few participants changed employer without changing work tasks and/or profession. Expectedly, a change of profession or employer usually implied a change of work tasks; 33.5 per cent of all participants reported changes of work tasks without a change of profession or employer. Further, 49.0 per cent of all employed participants reported no change whatsoever within the past four years.

The results of the three multinomial logistic regression analyses are shown in Table 2. Overall, each of the change groups, EL, RL and RS, showed patterns of socio-demographic factors, health and job factors which were different to those of the reference group of ES. Most pronounced were the differences in terms of 
Table 1. Socio-demographic factors, health and job factors in the full sample in 2014

\begin{tabular}{|c|c|c|c|}
\hline & $\mathrm{N}$ & $\%$ & Mean (SD) \\
\hline \multicolumn{4}{|l|}{ Socio-demographic factors: } \\
\hline Gender: & 2,835 & & \\
\hline Male & & 44.9 & \\
\hline Female & & 55.1 & \\
\hline Birth year: & 2,835 & & \\
\hline 1959 & & 45.1 & \\
\hline 1965 & & 54.9 & \\
\hline Partner: & 2,832 & & \\
\hline Yes & & 87.7 & \\
\hline No & & 12.3 & \\
\hline Job task requirement level: & 2,809 & & \\
\hline Un-/semi-skilled task & & 6.6 & \\
\hline Skilled task & & 55.7 & \\
\hline Complex task & & 18.3 & \\
\hline Highly complex task & & 19.4 & \\
\hline \multicolumn{4}{|l|}{ Health: } \\
\hline Mental health ${ }^{1}$ & 2,822 & & $55.6(10.1)$ \\
\hline Physical health ${ }^{1}$ & 2,822 & & $49.9(8.9)$ \\
\hline \multicolumn{4}{|l|}{ Job factors: } \\
\hline Weekly working hours: & 2,835 & & \\
\hline Full time & & 66.7 & \\
\hline Part time & & 29.0 & \\
\hline Marginal employment & & 4.3 & \\
\hline Seniority (in years) & 2,793 & & $16.4(10.5)$ \\
\hline Income level $(€)$ : & 2,787 & & \\
\hline Up to 450 & & 4.5 & \\
\hline $450-1,499$ & & 32.0 & \\
\hline $1,500-2,999$ & & 48.5 & \\
\hline 3,000 and more & & 15.0 & \\
\hline Physical workload: & 2,834 & & \\
\hline Never & & 23.1 & \\
\hline Up to one-quarter of the time & & 27.8 & \\
\hline More than one-quarter of the time & & 49.1 & \\
\hline Leadership quality ${ }^{1}$ & 2,770 & & $54.4(23.3)$ \\
\hline Influence at work ${ }^{1}$ & 2,833 & & $38.9(26.5)$ \\
\hline Possibilities for development ${ }^{1}$ & 2,835 & & $63.1(20.8)$ \\
\hline Work-family conflict ${ }^{1}$ & 2,830 & & $35.0(26.8)$ \\
\hline
\end{tabular}

Notes: SD: standard deviation. 1. Range from 0 to 100 . High scores indicate a high expression of the concept or good health. 


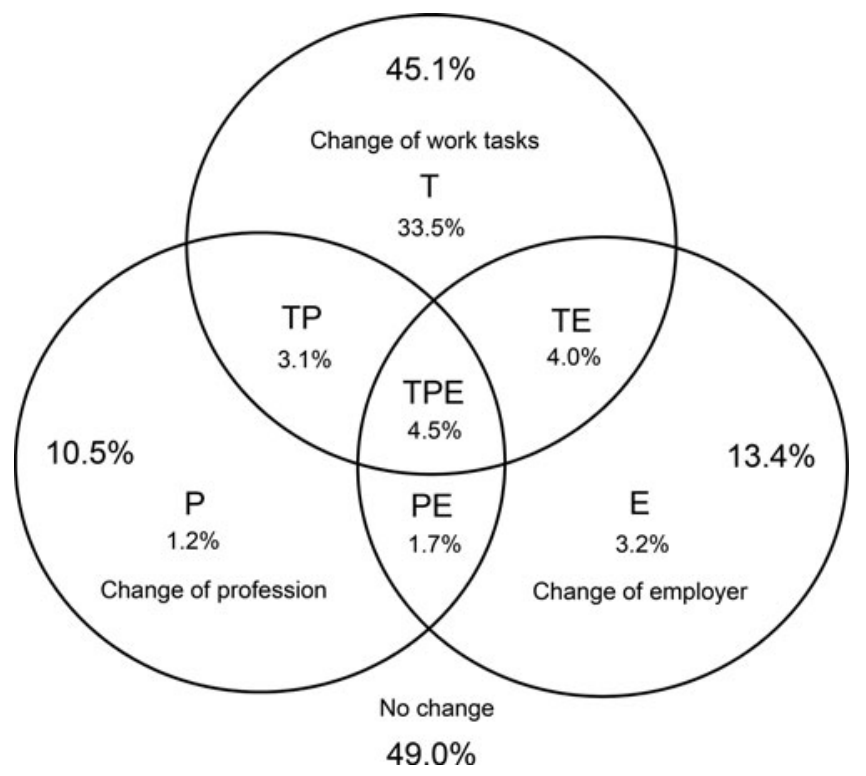

Figure 2. Combinations and overlap of occupational changes between 2014 and 2018 . Notes: $\mathrm{N}=2,781$. T: change of work tasks. P: change of profession. E: change of employer.

birth year, seniority, income level and leadership quality. Below, each group of EL, $\mathrm{RL}$ and RS is briefly characterised in contrast to the ES.

\section{Change of profession}

The leavers of profession (EL and RL) were younger, had more un-/semi-skilled tasks or highly complex tasks, less often worked part time, had a shorter seniority and more often had a lower income level. The RS showed a different pattern as they were younger, had poorer mental health, a shorter seniority, lower leadership quality and a higher work-family conflict.

\section{Change of employer}

The EL were younger, more often had a partner, had better physical health, a shorter seniority, more often had a lower income level and a lower leadership quality. The EL (employer) were the only group having more often a partner and reporting better physical health than the respective ES. Like the EL, the RL were less often part-time workers, had a shorter seniority and more often a lower income level, and they reported lower leadership quality. The RS (employer) showed the same pattern as the RS (profession).

\section{Change of work tasks}

The EL more often were female workers, had a shorter seniority, reported more possibilities for development and a higher work-family conflict. It was the only 
Table 2. Multinomial logistic regression

\begin{tabular}{|c|c|c|c|c|c|c|c|c|}
\hline & \multicolumn{2}{|c|}{ Change of profession } & \multicolumn{3}{|c|}{ Change of employer } & \multicolumn{3}{|c|}{ Change of work tasks } \\
\hline & $\mathrm{EL} / \mathrm{RL}$ & RS & EL & $\mathrm{RL}$ & RS & EL & $\mathrm{RL}$ & RS \\
\hline $\mathrm{N}$ & 254 & 465 & 175 & 96 & 353 & 168 & 662 & 235 \\
\hline \multicolumn{9}{|l|}{ Socio-demographic factors: } \\
\hline Gender (Ref. Female) & 0.906 & 0.885 & 0.908 & 1.398 & 0.962 & $0.413^{\star \star \star}$ & 0.884 & 0.818 \\
\hline Birth year (Ref. 1965) & $0.600^{\star * *}$ & $0.525^{\star \star \star}$ & $0.695^{\star}$ & 0.775 & $0.738^{\star}$ & 0.723 & 0.970 & 0.899 \\
\hline Partner (Ref. Yes) & 0.985 & 1.269 & $0.507^{\star}$ & 0.735 & 0.993 & 1.532 & 0.914 & 1.084 \\
\hline \multicolumn{9}{|c|}{ Job task requirement level (Ref. Skilled task): } \\
\hline Un-/semi-skilled task & $1.732^{\star}$ & 1.361 & 1.422 & 0.880 & 1.096 & 0.496 & 0.772 & 0.831 \\
\hline Complex task & 1.292 & 0.877 & 0.761 & 0.917 & 0.950 & 1.124 & 1.145 & 1.329 \\
\hline Highly complex task & $1.712^{\star \star}$ & 1.088 & 1.455 & 0.735 & 1.103 & 1.126 & 1.037 & 1.273 \\
\hline \multicolumn{9}{|l|}{ Health: } \\
\hline Mental health ${ }^{1}$ & 0.994 & $0.979^{\star \star \star}$ & 0.987 & 0.991 & $0.986^{\star}$ & 0.995 & $0.983^{\star \star}$ & 0.989 \\
\hline Physical health $^{1}$ & 0.999 & 0.999 & $1.029^{\star \star}$ & 0.989 & 0.996 & 0.984 & $0.987^{\star}$ & 1.009 \\
\hline \multicolumn{9}{|l|}{ Job factors: } \\
\hline \multicolumn{9}{|c|}{ Weekly working hours (Ref. Full time): } \\
\hline Part time & $0.590^{\star \star}$ & 1.172 & 0.811 & $0.499^{\star}$ & 0.845 & 0.742 & 0.962 & 1.002 \\
\hline Marginal employment & 0.382 & 1.138 & 0.713 & 0.423 & 0.460 & 0.720 & 0.809 & 1.530 \\
\hline Seniority (in years) & $0.961^{\star \star *}$ & $0.978^{\star \star *}$ & $0.894^{\star \star \star}$ & $0.918^{\star \star \star}$ & $0.971^{\star \star \star}$ & $0.980^{*}$ & $1.011^{*}$ & 0.989 \\
\hline
\end{tabular}


Table 2. (Continued.)

\begin{tabular}{|c|c|c|c|c|c|c|c|c|}
\hline & \multicolumn{2}{|c|}{ Change of profession } & \multicolumn{3}{|c|}{ Change of employer } & \multicolumn{3}{|c|}{ Change of work tasks } \\
\hline Up to 450 & $4.150^{\star \star}$ & 0.544 & $3.802^{*}$ & 2.440 & 0.876 & 1.448 & 0.522 & $0.150^{\star}$ \\
\hline $450-1,499$ & $2.176^{\star \star \star}$ & 0.965 & $2.301^{\star \star \star}$ & $2.504^{\star \star}$ & 1.322 & 1.245 & 0.993 & $0.641^{*}$ \\
\hline Up to one-quarter of the time & 0.852 & 0.995 & 1.052 & 1.002 & 0.906 & 0.905 & 1.110 & 1.105 \\
\hline More than one-quarter of the time & 0.879 & 1.158 & 1.042 & 0.845 & 1.105 & 0.850 & $1.317^{\star}$ & 1.454 \\
\hline Leadership quality ${ }^{1}$ & 0.994 & $0.989^{\star \star \star}$ & $0.982^{\star \star \star}$ & $0.981^{\star \star \star}$ & $0.975^{\star \star \star}$ & 0.992 & $0.995^{*}$ & $0.992^{*}$ \\
\hline Influence at work ${ }^{1}$ & 0.999 & 1.000 & 1.004 & 0.994 & 1.003 & 1.006 & 1.000 & 1.005 \\
\hline
\end{tabular}

Notes: Values are odds ratios/Exp(B). EL: enthusiastic leavers. RL: reluctant leavers. RS: reluctant stayers. ES: enthusiastic stayers. Ref.: reference group. The change groups refer to changes between 2014 and 2018. ES was the reference group in all three models. Socio-demographic factors, health and job factors were surveyed in 2014. 1. Range from 0 to 100. High scores indicate a high expression of the concept or good health.

Significance levels: ${ }^{\star} p<0.05,{ }^{\star \star} p<0.01,{ }^{* \star *} p<0.001$. 
group more often reporting higher income levels than the respective ES. The large group of RL showed another noticeable pattern as they more often reported both poorer mental and physical health, a longer seniority, a high physical workload, lower leadership quality, more possibilities for development and a higher workfamily conflict. This group was the only one reporting significantly poorer physical health, a longer seniority and more often performing physical work than the reference group. Also, the RS exhibited a characteristic pattern: although they less often reported lower income levels, many work indicators were rated adversely: lower leadership quality, less possibilities for development (only significant in this group) and a higher work-family conflict.

The underlying main reasons for all voluntary and desired changes are presented in Table 3. Responses in italics are in concordance with findings from the multinomial logistic regression analyses. Here, three aspects stand out. First, some main reasons were mentioned frequently such as better working conditions (especially among RS), better salary and occupational career. Second, the most frequent main reasons for the three types of occupational change differ clearly. While the reasons better working conditions and better salary are prominent among employer changes, the reason avoiding unemployment is common among change of profession and the reason want to do something new is common among changes of work tasks. Last, the most frequent main reasons for EL and RS differ in some respect. For example, while avoiding unemployment is common among EL of profession, only few RS aimed to change profession to avoid unemployment.

\section{Discussion}

Our results showed that in Germany, occupational change is common among older workers. In the period of four years, almost half of the participants had changed work tasks, and even the proportions of participants who had changed employer or profession were considerable. In many cases the occupational changes coincide. Most changes of profession were accompanied by employer changes, while changes of work tasks often took place without further occupational changes. In addition to actual changes, however, it was also shown that many workers often would have liked to have changed without doing so. Our results confirm that the occupational change groups EL, RL and RS differ from the ES with respect to sociodemographics, job factors and health. Additionally, the self-reported main reasons for realised or wanted changes highlight differences between the three types of change and the stayers and leavers investigated in this study. In the following, we will discuss the results structured by the three types of occupational change.

\section{Change of profession}

In our study, changes of profession were the least common type of change (10.5\% of all participants). According to Blau and Lunz (1998), older workers are likely to have found jobs with a high work-life balance, they are more committed to their profession and have less need to change. Their mobility self-efficacy, i.e. the perceived ability to change profession, may decrease with age and seniority, which 
Table 3. Main reasons for change among enthusiastic leavers and reluctant stayers

\begin{tabular}{|c|c|c|c|c|}
\hline \multirow{8}{*}{$\begin{array}{l}\text { Change of } \\
\text { profession }^{1}\end{array}$} & \multicolumn{2}{|c|}{ Enthusiastic leavers } & \multicolumn{2}{|c|}{ Reluctant stayers } \\
\hline & $N=291^{2}$ & & $N=419$ & \\
\hline & 14.4 & Occupational career & 31.0 & $\begin{array}{l}\text { Better working } \\
\text { conditions }\end{array}$ \\
\hline & 11.0 & $\begin{array}{l}\text { Avoiding } \\
\text { unemployment }\end{array}$ & 13.4 & Health reasons \\
\hline & 10.3 & $\begin{array}{l}\text { Better working } \\
\text { conditions }\end{array}$ & 11.8 & Better salary \\
\hline & 7.6 & Health reasons & 10.4 & Occupational career \\
\hline & 5.5 & Better working hours & 9.6 & Better working hours \\
\hline & 5.2 & Better salary & 5.3 & Work-family conflict \\
\hline \multirow{7}{*}{$\begin{array}{l}\text { Change of } \\
\text { employer }\end{array}$} & $N=199$ & & $N=370$ & \\
\hline & 29.1 & $\begin{array}{l}\text { Better working } \\
\text { conditions }\end{array}$ & 42.4 & $\begin{array}{l}\text { Better working } \\
\text { conditions }\end{array}$ \\
\hline & 15.1 & Better salary & 15.7 & Better salary \\
\hline & 14.1 & Occupational career & 7.3 & Better working hours \\
\hline & 10.1 & Better working hours & 6.8 & Occupational career \\
\hline & 8.0 & Work-family conflict & 6.5 & Work-family conflict \\
\hline & 5.5 & Health reasons & 6.2 & Health reasons \\
\hline \multirow{7}{*}{$\begin{array}{l}\text { Change of work } \\
\text { tasks }\end{array}$} & $N=182$ & & $N=249$ & \\
\hline & 23.6 & Occupational career & 26.1 & $\begin{array}{l}\text { Better working } \\
\text { conditions }\end{array}$ \\
\hline & 20.3 & $\begin{array}{l}\text { Want to do } \\
\text { something new }\end{array}$ & 20.5 & $\begin{array}{l}\text { Want to do } \\
\text { something new }\end{array}$ \\
\hline & 17.0 & $\begin{array}{l}\text { Better working } \\
\text { conditions }\end{array}$ & 20.1 & Occupational career \\
\hline & 14.8 & Health reasons & 12.0 & Health reasons \\
\hline & 8.2 & Better salary & 8.4 & Better working hours \\
\hline & 4.9 & Better working hours & 4.8 & Better salary \\
\hline
\end{tabular}

Notes: Values are percentages. The first six most frequent main reasons are displayed. 1. No differentiation between enthusiastic and reluctant leavers. 2. Missing responses $=74$. Italic: In concordance with findings from the multinomial logistic regression analyses.

may explain the relatively few changes of profession and why only one-third of all RS attempted to change profession (Otto et al., 2009). This is also in line with our findings that EL/RL and RS have a significantly shorter seniority than the ES. Thus, changers of profession are a special group often driven by financial aspects of the job, which is reflected by the main reasons better salary and by the fact that leavers more often reported a lower income level. Further, the group is characterised by employment security needs, expressed in the main reasons occupational career and avoiding unemployment. 
Of all three forms of occupational change, the proportion of RS was clearly highest (17.6\%). The reluctance to change profession seems justified as older workers are faced with limited opportunities to change; a change of profession is a greater step than an employer change and bears substantial risks for employment, finances and professional identity (Bailey and Hansson, 1995). Although the propensity to change profession may be low among older workers, they may find themselves forced to change profession when the person-job fit becomes low, be it because of age-related changes in health and functioning or changes in work demands (Trinczek, 2011; Huysse-Gaytandjieva et al., 2013). In our sample, the RS reported poorer mental health while wanting a change due to health reasons and reported lower leadership quality and a higher work-family conflict, which reflects the person-job misfit which, indeed, Hom et al. (2012) have attributed to the RS. Also their predominantly selected main reasons for the desire to change better working conditions and work-family conflict correspond to the results in the regression analysis and the motivational states by Hom et al. (2012). Our findings are in line with Canivet et al. (2017), who showed that older workers in secure employment are often reluctant to change profession, despite possible negative impacts of their current jobs on their mental health.

\section{Change of employer}

In relation to changes of profession, employer changes seem to be more common in Germany: 13.4 per cent of all participants changed employer, 7.1 per cent voluntarily. According to research, these voluntary employer changes (EL) are associated with positive consequences for the individual: increase in work ability, leadership quality, social support from colleagues, possibilities for development, and a decrease in work-family conflict and quantitative demands (Garthe and Hasselhorn, 2020), an increase of status and self-esteem, decreased physical strain, less burnout, better psycho-social health (Canivet et al., 2017) and higher job satisfaction (Chadi and Hetschko, 2014). In line with Hom et al. (2012), who assumed that EL may change to follow relocating spouses and who have conflicts with supervisors, in our study, the EL more often had a partner and reported lower leadership quality. Moreover, the misfit between the former jobs and the workers is reflected by the most frequently reported main reason for changing: better working conditions. As reviewed by Hom et al. (2012), EL need to have the physical capacity to change, e.g. health resources. Indeed, our results showed that the EL were the only group who reported better physical health than the respective ES. Additionally, financial reasons were prominent among the EL, who often had a lower income and changed to increase their income.

However, our results also show that many workers would like to change their employer (RS), but apparently cannot. They may find themselves in a 'locked' work situation (Huysse-Gaytandjieva et al., 2013), e.g. due to restrictive external factors such as family-related immobility, a temporary employment contract (Hom et al., 2012) or because changes remain risky as it is difficult for older workers to find a new job (Heywood and Jirjahn, 2016). However, reluctant staying bears personal risks for motivation, work performance (Hom et al., 2012) and mental health (Canivet et al., 2017). These findings are in line with our results as the RS 
had poorer mental health and lower leadership quality. However, although they had significantly poorer mental health, only few RS wanted to change for health reasons. The most frequently reported main reason, better working conditions, rather reflects a person-job misfit.

While many older workers wanted to change their employer, our data also indicated that a considerable degree of older workers in Germany were forced to change due to dismissal (RL). Such a reluctant change is usually preceded by conflicts with supervisors, poor performance or when an entire company is affected, such as layoffs, or when a company closes down (Canivet et al., 2017). Here, the analysis confirms that the RL reported a significantly lower leadership quality than the ES, which may represent these conflicts.

\section{Change of work tasks}

The fact that in our study almost every other worker reported significant work task changes during the past three years indicates that work is in constant change requiring older workers to apply individual adaptation strategies ( $\mathrm{Ng}$ and Law, 2014). The high proportion of workers with employer-induced changes is striking (RL, 24.8\%). A crucial question is whether these changes occurred with or without considering the individual workers' needs. Job enrichment, job rotation or job enlargement are positive examples of how employers may change the work tasks of their employees to improve their work and professional development (Chung and Ross, 1977). However, the high proportion of employer-induced changes may in part also be due to organisational restructuring, where the single worker will find less consideration (Jimmieson et al., 2004). Our analysis allows more insight into this probably heterogeneous group of RL and shows that they clearly differ from RL of profession and employer. RL (work tasks) reported both poorer mental and physical health while more often having high physical workload. One interpretation of these findings is that the employers reacted to the reduced physical and mental resources of the workers and attempted to alleviate the physically demanding job situation by adapting the work tasks. Although the RL reported lower leadership quality, they apparently had more possibilities for development in their jobs, which may be indicative of a supportive work organisation. The group also stands out because they had a significantly longer seniority than the ES, thereby possibly constituting a core workforce in the organisation with strong ties to the employer. This may also contribute to why their employers would rather change their work tasks than dismiss them.

However, many older workers changed work tasks on their own initiative (EL) to do something new, for better working conditions or health reasons, which is in line with the theory on job crafting, where workers are regarded as active constructors of their work (Wrzesniewski and Dutton, 2001) and where workers improve and adjust their work with the aim of improving their work ability (Tims et al., 2013). Our findings, that EL more often had a higher income level, had more possibilities for development and changed to promote the occupational career and to do something new, indicate that EL (work tasks) have more flexibility to initiate work task changes within their jobs. They may constitute a somewhat privileged group with a higher status within the organisation, more income, and more 
flexibility and possibilities to adapt their work tasks. Such flexibility increases the structural and social resources of the employees, their wellbeing, engagement and job satisfaction (Tims et al., 2013), and the motivation to work longer among older workers (Moen et al., 2016). It is noticeable that this group reported a higher work-family conflict, while this conflict was a rarely mentioned main reason for the change.

With respect to the RS, a range of obstacles for work task changes may be thought of. Some types of jobs are difficult to change, such as assembly-line work or jobs requiring high task interdependence with co-workers (Wrzesniewski and Dutton, 2001). For workers in low hierarchy levels and/or with low decision latitude, changes on their own initiative may be more difficult to realise although they may exhibit the highest need, due to poorer working conditions, higher work strain and lower wages (Siegrist et al., 2009). These assumptions are supported by our analyses as the RS had fewer possibilities for development, reported a lower leadership quality and would like to change to improve their working conditions. Yet, they reported higher income levels.

Like the EL and RL, the RS (work tasks) reported higher work-family conflicts, but did not mention it as reason for their desire to change. This follows a certain logic as - in contrast to changes of profession or employer - work task changes may have less potential to improve a work-family conflict. However, the significantly higher work-family conflict in the three groups EL, RL and RS may also be indicative of a specifically low work-family conflict in the reference group, the ES (work tasks). The latter may constitute a selective group of workers in the organisations who are widely satisfied with their work situation, just as the typical ES as characterised by Hom et al. (2012).

In summary, our results provide a broad empirical overview of changes of profession, employer and work tasks, and a characterisation of the enthusiastic as well as reluctant stayers and leavers among older workers. Each change group revealed a characteristic pattern in terms of socio-demographic background, health and work situation. Most of our findings on the three forms of occupational change could be plausibly explained on the basis of existing theoretical and empirical literature. Interestingly, the different occupational change groups for all three forms of occupational change were in line with the group descriptions by Hom et al. (2012), although their motivational states of staying and leaving are based on reviewing employer changes.

\section{Strengths and limitations}

Strengths of our study are the large size allowing for in-depth sub-group analyses, the age-homogenous sample, the longitudinal study design and the representativeness for the German socially insured working population of similar age. Another strength of this study is that we could measure actual changes rather than using proxy measures such as change intentions or job search.

Limitations to our study are that we were not able to measure multiple changes, only the last change was registered, that we could not differentiate between voluntary and involuntary changes of profession, and that we cannot exclude misclassification of occupational change in our study. 


\section{Conclusions}

Occupational changes are a normal part of the working life. The results of the lidA Cohort study indicate that this is also the case for older workers in Germany: in the course of four years, every second older employee had an occupational change. Our findings indicate that these changes are multifaceted. Employees change profession, employer and/or work tasks to a different degree, under different circumstances, among different groups of employees and for different reasons. While in most of the cases the older workers change profession and employer voluntarily, changes of work tasks happen predominantly involuntarily due to an employer's decision.

However, occupational changes do not only happen, they are even more often desired and unfulfilled. Changes in later working life are risky and opportunities as well as resources may be lacking. Our data show that there are more older workers with a wish to change profession, employer or work tasks (RS) than those who are actually changing on their own initiative (EL). The RS stand out due to poorer mental health and lower leadership quality than the ES. Thus, there is a risk that desired and yet unfulfilled changes have negative consequences for older workers, e.g. on health, wellbeing and motivation, and for the organisation, because they may constitute a risk group to poor performance and low work motivation.

Yet, occupational changes - when successful - may provide substantial chances for the worker, the enterprise and even the national economy. It is surprising that in times of ageing populations, the topic of occupational change among older workers and its potential for employment participation does not receive much attention in society, policy and research.

So far, empirical research in the field of occupational change has largely focused on employer changes, however, a stronger focus on the other forms of occupational change is needed. Further, more evidence is needed on immediate, medium- and even long-term effects of occupational changes among older workers, with respect to wellbeing, health, work ability, wealth and employment participation in later working life. Finally, the group of RS requires more scientific attention. There is a need to investigate what prevents these older workers from attempting and realising a desired change, how reluctant staying will affect the older workers' personal and work situations in the long run, and how these needs and desires for change can be met by human resource management and social policies.

Author contributions. NG and HMH designed the study, NG performed the analyses, NG wrote the first draft of the manuscript, and $\mathrm{HMH}$ and NG critically reviewed and revised the manuscript and approved the final article.

Financial support. This work was supported by the Ministry of Culture and Science of the German State of North Rhine-Westphalia; and the German Social Accident Insurance, DGUV (FP 403). The funding institutions did not have any influence on the design of the study, the data collection, analysis and interpretation of the data nor on the writing of the manuscript.

Conflict of interest. The authors declare no conflicts of interest.

Ethical standards. Design and conduct of the lidA study have been approved by the Ethics Committee of the University of Wuppertal dated from 5 December 2008 and 20 November 2017 (MS/BB 171025 Hasselhorn). Participants were fully informed about the aim and procedure of this study prior to giving consent to participate. All procedures performed in studies involving human participants were in accordance with the ethical standards of the institutional and/or national research committee and with the 1964 Helsinki declaration and its later amendments or comparable ethical standards. 


\section{References}

Adams SJ (2004) Employer-provided health insurance and job change. Contemporary Economic Policy 22, 357-369.

Alcover C-M and Topa G (2018) Work characteristics, motivational orientations, psychological work ability and job mobility intentions of older workers. PLOS ONE 13, 1-24.

Aleksandrowicz P, Zieschang H, Bräunig D and Jahn F (2014) Horizontal career changes as an alternative to premature exit from work. International Journal of Occupational Safety and Ergonomics 20, 65-76.

Allen DG, Hancock JI, Vardaman JM and Mckee DN (2014) Analytical mindsets in turnover research. Journal of Organizational Behavior 35, 61-86.

Bailey LL and Hansson RO (1995) Psychological obstacles to job or career change in late life. Journals of Gerontology: Psychological Sciences and Social Sciences 50B, 280-288.

Blau G and Lunz M (1998) Testing the incremental effect of professional commitment on intent to leave one's profession beyond the effects of external, personal, and work-related variables. Journal of Vocational Behavior 52, 260-269.

Boswell WR, Shipp AJ, Payne SC and Culbertson SS (2009) Changes in newcomer job satisfaction over time. Examining the pattern of honeymoons and hangovers. Journal of Applied Psychology 94, 844-858.

Canivet C, Aronsson G, Bernhard-Oettel C, Leineweber C, Moghaddassi M, Stengård J, Westerlund H and Östergren P-O (2017) The negative effects on mental health of being in a non-desired occupation in an increasingly precarious labour market. SSM - Population Health 3, 516-524.

Carless SA and Arnup JL (2011) A longitudinal study of the determinants and outcomes of career change. Journal of Vocational Behavior 78, 80-91.

Chadi A and Hetschko C (2014) The magic of the new: how job changes affect job satisfaction. Institut für Arbeitsrecht und Arbeitsbeziehungen in der Europäischen Union Discussion Paper Series in Economics 5.

Chung KH and Ross MF (1977) Differences in motivational properties between job enlargement and job enrichment. Academy of Management Review 2, 113-122.

Conen W, Henkens K and Schippers J (2014) Ageing organisations and the extension of working lives. A case study approach. Journal of Social Policy 43, 773-792.

Crawford JO, Graveling RA, Cowie HA and Dixon K (2010) The health safety and health promotion needs of older workers. Occupational Medicine 60, 184-192.

De Raeve L, Jansen NWH, van den Brandt PA, Vasse R and Kant IJ (2008) Interpersonal conflicts at work as a predictor of self-reported health outcomes and occupational mobility. Occupational and Environmental Medicine 66, 16-22.

Feldman DC and Ng TWH (2007) Careers. Mobility, embeddedness, and success. Journal of Management 33, 350-377.

Fernet C, Trépanier S-G, Demers M and Austin S (2017) Motivational pathways of occupational and organizational turnover intention among newly registered nurses in Canada. Nursing Outlook 65, 444-454.

Garthe N and Hasselhorn HM (2020) Leaving and staying with the employer - Changes in work, health, and work ability among older workers. International Archives of Occupational and Environmental Health 94, 85-93.

Grund C (2009) Jobpräferenzen und Arbeitsplatzwechsel. Zeitschrift für Personalforschung 23, 66-72.

Hasselhorn HM (2020) Wie lange wollen und können Erwerbstätige in Deutschland arbeiten? Deutsche Rentenversicherung 75, 4, 453-474.

Hasselhorn HM, Peter R, Rauch A, Schröder H, Swart E, Bender S, Du Prel J-B, Ebener M, March S, Trappmann M, Steinwede J and Müller BH (2014) Cohort profile. The lidA cohort study - a German cohort study on work, age, health and work participation. International Journal of Epidemiology 43, 1736-1749.

Heywood JS and Jirjahn U (2016) The hiring and employment of older workers in Germany. A comparative perspective. Zeitschrift für Arbeitsmarktforschung 49, 349-366.

Hom PW, Mitchell TR, Lee TW and Griffeth RW (2012) Reviewing employee turnover. Focusing on proximal withdrawal states and an expanded criterion. Psychological Bulletin 138, 831-858.

Hom PW, Lee TW, Shaw JD and Hausknecht JP (2017) One hundred years of employee turnover theory and research. Journal of Applied Psychology 102, 530-545. 
Huysse-Gaytandjieva A, Groot W and Pavlova M (2013) A new perspective on job lock. Social Indicators Research 112, 587-610.

Jahn F and Ulbricht S (2011) Mein nächster Beruf-Personalentwicklung für Berufe mit begrenzter Tätigkeitsdauer: Teil 1: Modellprojekt in der stationären Krankenpflege (Report No. 17). Berlin: iga.

Jimmieson NL, Terry DJ and Callan VJ (2004) A longitudinal study of employee adaptation to organizational change. The role of change-related information and change-related self-efficacy. Journal of Occupational Health Psychology 9, 11-27.

Kenny GP, Groeller H, McGinn R and Flouris AD (2016) Age, human performance, and physical employment standards. Applied Physiology, Nutrition, and Metabolism 41, 92-107.

Klaus D, Engstler H, Mahne K, Wolff JK, Simonson J, Wurm S and Tesch-Römer C (2017) Cohort profile. The German Ageing Survey (DEAS). International Journal of Epidemiology 46, 1105-1105g.

Kooij DTAM, Nijssen H, Bal PM, van der Kruijssen DTF and Truxillo D (2020) Crafting an interesting job. Stimulating an active role of older workers in enhancing their daily work engagement and job performance. Work, Aging and Retirement 6, 165-174.

Kuijpers E, Kooij DTAM and van Woerkom M (2020) Align your job with yourself. The relationship between a job crafting intervention and work engagement, and the role of workload. Journal of Occupational Health Psychology 25, 1-16.

Liljegren M and Ekberg K (2008) The longitudinal relationship between job mobility, perceived organizational justice, and health. BMC Public Health 8, 164.

Liljegren M and Ekberg K (2009) Job mobility as predictor of health and burnout. Journal of Occupational and Organizational Psychology 82, 317-329.

Mantler J, Godin J, Cameron SJ and Horsburgh ME (2015) Cynicism in hospital staff nurses. The effect of intention to leave and job change over time. Journal of Nursing Management 23, 577-587.

Moen P, Kojola E, Kelly EL and Karakaya Y (2016) Men and women expecting to work longer. Do changing work conditions matter? Work, Aging and Retirement 2, 321-344.

Morris L (2009) Quits and job changes among home care workers in Maine. The role of wages, hours, and benefits. The Gerontologist 49, 635-650.

Ng ESW and Law A (2014) Keeping up! Older workers' adaptation in the workplace after age 55. Canadian Journal on Aging 33, 1-14.

Nisic N and Trübswetter P (2012) Berufswechsler in Deutschland und Großbritannien. SOEPpapers 442, $1-14$.

Nouri H and Parker RJ (2013) Career growth opportunities and employee turnover intentions in public accounting firms. British Accounting Review 45, 138-148.

Nübling M, Andersen HH and Mühlbacher A (2006) Data Documentation 16. Entwicklung eines Verfahrens zur Berechnung der körperlichen und psychischen Summenskalen auf Basis der SOEPVersion des SF 12 (Algorithmus). Berlin: Deutsches Institut für Wirtschaftsforschung.

Otto K, Dette-Hagenmeyer DE and Dalbert C (2009) Occupational mobility in members of the labor force. Explaining the willingness to change occupations. Journal of Career Development 36, 262-288.

Pak K, Kooij DTAM, Lange AH de and van Veldhoven MJPM (2019) Human Resource Management and the ability, motivation and opportunity to continue working. A review of quantitative studies. Human Resource Management Review 29, 336-352.

Pejtersen JH, Kristensen TS, Borg V and Bjorner JB (2010) The second version of the Copenhagen Psychosocial Questionnaire. Scandinavian Journal of Public Health 38, 8-24.

Reineholm C, Gustavsson M, Liljegren M and Ekberg K (2012) The importance of work conditions and health for voluntary job mobility. A two-year follow-up. BMC Public Health 12, 682.

Rubenstein AL, Eberly MB, Lee TW and Mitchell TR (2018) Surveying the forest. A meta-analysis, moderator investigation, and future-oriented discussion of the antecedents of voluntary employee turnover. Personnel Psychology 71, 23-65.

Schröder H, Kersting A, Gilberg R and Steinwede J (2013) Methodenbericht zur Haupterhebung lidA leben in der Arbeit. FDZ-Methodenreport 01/2013. Bonn: infas Institut für angewandte Sozialwissenschaften GmbH.

Siegrist J, Wege N, Pühlhofer F and Wahrendorf M (2009) A short generic measure of work stress in the era of globalization. Effort-reward imbalance. International Archives of Occupational and Environmental Health 82, 1005-1013. 
Simon M, Müller BH and Hasselhorn HM (2010) Leaving the organization or the profession - a multilevel analysis of nurses' intentions. Journal of Advanced Nursing 66, 616-626.

Stengård J, Bernhard-Oettel C, Berntson E, Leineweber C and Aronsson G (2016) Stuck in a job. Being 'locked-in' or at risk of becoming locked-in at the workplace and well-being over time. Work and Stress 30, 152-172.

The American Association for Public Opinion Research (2016) Standard Definitions: Final Dispositions of Case Codes and Outcome Rates for Surveys. Washington, DC: The American Association for Public Opinion Research.

Tims M, Bakker AB and Derks D (2013) The impact of job crafting on job demands, job resources, and well-being. Journal of Occupational Health Psychology 18, 230-240.

Trevor CO (2001) Interactions among actual ease-of-movement determinations and job satisfaction in the prediction of voluntary turnover. Academy of Management Journal 44, 621-638.

Trinczek R (2011) Überlegungungen zum Wandel von Arbeit. WSI-Mitteilungen 11, 606-614.

van Hooft EAJ, Born MP, Taris TW and van der Flier H (2005) Predictors and outcomes of job search behavior. The moderating effects of gender and family situation. Journal of Vocational Behavior 67, 133-152.

Ware JE, Kosinski M and Keller SD (1995) SF-12: How to Score the SF-12 Physical and Mental Health Summary Scales. Boston, MA: The Health Institut, New England Medical Center.

Ware JE, Kosinski M and Keller SD (1996) A 12-Item Short-Form Health Survey. Construction of scales and preliminary tests of reliability and validity. Medical Care 34, 220-233.

Weng Q and McElroy JC (2012) Organizational career growth, affective occupational commitment and turnover intentions. Journal of Vocational Behavior 80, 256-265.

Wong CM and Tetrick LE (2017) Job crafting. Older workers' mechanism for maintaining person-job fit. Frontiers in Psychology 8, 1548.

Wrzesniewski A and Dutton JE (2001) Crafting a job: revisioning employees as active crafters of their work. Academy of Management Review 26, 179-201.

Cite this article: Garthe N, Hasselhorn HM (2022). Changes of profession, employer and work tasks in later working life: an empirical overview of staying and leaving. Ageing \& Society 42, 2393-2413. https:// doi.org/10.1017/S0144686X21000088 